\title{
Effects of Lumbar Strengthening Exercise in Lower-Limb Amputees With Chronic Low Back Pain
}

\author{
Min Kyung Shin, $\mathrm{MD}^{1}$, Hee Seung Yang, $\mathrm{MD}^{1}$, Hea-Eun Yang, $\mathrm{MD}^{1}$, Dae Hyun Kim, $\mathrm{MD}^{1}$, \\ Bo Ram Ahn, MD ${ }^{1}$, Hyup Kwon, PT $^{1}$, Ju Hwan Lee, PT $^{1}$, Suk Jung, PT $^{1}$, Hyun Chul Choi, PT $^{1}$, \\ Sun Keaung Yun, RN, $\mathrm{MS}^{1}$, Dong Young Ahn, $\mathrm{CPO}^{2}$, Woo Sob Sim, $\mathrm{CPO}^{2}$
}

${ }^{1}$ Department of Physical Medicine and Rehabilitation, ${ }^{2}$ Center of Prosthetics and Orthotics, Veterans Health Service Medical Center, Seoul, Korea

\begin{abstract}
Objective To analyze the effect of lumbar strengthening exercise in lower-limb amputees with chronic low back pain.

Methods We included in this prospective study 19 lower-limb amputees who had experienced low back pain for longer than 6 months. Participants were treated with 30-minute lumbar strengthening exercises, twice weekly, for 8 weeks. We used the visual analog scale (VAS), and Oswestry low back pain disability questionnaire, and measured parameters such as iliopsoas length, abdominal muscle strength, back extensor strength, and back extensor endurance. In addition, we assessed the isometric peak torque and total work of the trunk flexors and extensors using isokinetic dynamometer. The pre- and post-exercise measurements were compared.

Results Compared with the baseline, abdominal muscle strength (from $4.4 \pm 0.7$ to $4.8 \pm 0.6$ ), back extensor strength (from 2.6 \pm 0.6 to $3.5 \pm 1.2$ ), and back extensor endurance (from $22.3 \pm 10.7$ to $46.8 \pm 35.1$ ) improved significantly after 8 weeks. The VAS decreased significantly from $4.6 \pm 2.2$ to $2.6 \pm 1.6$ after treatment. Furthermore, the peak torque and total work of the trunk flexors and extensors increased significantly $(\mathrm{p}<0.05)$.

Conclusion Lumbar strengthening exercise in lower-limb amputees with chronic low back pain resulted in decreased pain and increased lumbar extensor strength. The lumbar strengthening exercise program is very effective for lower-limb amputees with chronic low back pain.
\end{abstract}

Keywords Amputation, Low back pain, Exercise, Muscle strength, Rehabilitation

Received May 16, 2017; Accepted July 3, 2017

Corresponding author: Hee Seung Yang

Department of Physical Medicine and Rehabilitation, Veterans Health Service Medical Center, 53 Jinhwangdo-ro 61-gil, Gangdong-gu, Seoul 05368, Korea. Tel: +82-2-2225-1498, Fax: +82-2-2225-1579, E-mail: yang7310@naver.com

ORCID: Min Kyung Shin (http://orcid.org/0000-0003-1184-9715); Hee Seung Yang (http://orcid.org/0000-0003-2492-7065); Hea-Eun Yang (http:// orcid.org/0000-0002-4449-7288); Dae Hyun Kim (http://orcid.org/0000-0002-5065-4286); Bo Ram Ahn (http://orcid.org/0000-0003-4236-6775); Hyup Kwon (http://orcid.org/0000-0003-2141-9161); Ju Hwan Lee (http://orcid.org/0000-0001-6524-6966); Suk Jung (http://orcid.org/0000-0003-19807691); Hyun Chul Choi (http://orcid.org/0000-0003-4839-3408); Sun Keaung Yun (http://orcid.org/0000-0002-7177-6098); Dong Young Ahn (http:// orcid.org/0000-0002-3925-9525); Woo Sob Sim (http://orcid.org/0000-0002-0760-3918).

() This is an open-access article distributed under the terms of the Creative Commons Attribution Non-Commercial License (http://creativecommons.org/ licenses/by-nc/4.0) which permits unrestricted noncommercial use, distribution, and reproduction in any medium, provided the original work is properly cited. Copyright $\odot 2018$ by Korean Academy of Rehabilitation Medicine 


\section{INTRODUCTION}

Chronic low back pain is defined as lumbar pain that lasts for longer than 12 weeks. Approximately $50 \%$ of the general population will suffer from chronic low back pain [1], and $70 \%$ of these individuals will experience acute low back pain at least once [2]. Patients with chronic low back pain experience atrophy of the trunk muscle and joint contractures, leading to a reduction in physical activity and aggravated muscle stiffness and strain, resulting in further pain. Hence, weakening of the trunk muscle can be a major source of lumbar spine pain and repetitive injury. Therefore, it is crucial that patients with chronic low back pain increase their levels of physical activity and improve their trunk muscle strength for stability. Numerous studies have demonstrated the positive effects of exercise on chronic low back pain [3-5].

It is commonly accepted that lower limb amputees frequently experience chronic pain. Although only phantom pain and stump pain are associated with lower-limb amputations, recent studies have reported that low back pain also occurs at a high frequency in these individuals. The frequency of low back pain is relatively high at $71 \%$ in lower-limb amputees [6-8].

The incidence of low back pain in these patients is influenced by several biochemical factors. Abnormal spinal kinematics resulting from the prosthetic gait is likely to be one of the most important factors. The mechanical demand on the low back is high for low-limb amputees while walking due to increased and asymmetric trunk motion [9]. Increase in mechanical demand during daily activities such as walking requires larger responses from internal trunk muscles to maintain the stability and equilibrium of the spine, and large spinal loads increase the risk of low back pain.

Ehde et al. [7] evaluated 255 lower-limb amputees who had been amputated for longer than 6 months, and examined the frequency and severity of low back pain in disrupting daily life. Among the participants, $52 \%$ responded that they experienced constant low back pain. Furthermore, 22\% reported severe disruption of daily life by low back pain within the past 3 months, $23 \%$ reported disruption of leisure life and family life, and $28 \%$ reported disruption of school and housework. Hence, low back pain is regarded as an important factor that induces secondary disability in lower limb amputees.
Unlike regular people, ill-fitting sockets and prostheses, poor alignment, abnormal position, limb length discrepancy, and length of amputation are risk factors for low back pain in amputees. However, lumbar muscle strength, which is considered the most important factor affecting low back pain in regular people, has not been assessed in lower-limb amputees. Despite the large number of studies investigating low back pain treatments in regular people, there are no studies on the effects of exercise on low back pain in lower-limb amputees. Therefore, the aim of this study was to develop a lumbar strengthening exercise program for such amputees and analyze the therapeutic effects thereof.

\section{MATERIALS AND METHODS}

\section{Participants}

The study subjects consisted of patients who visited the rehabilitation outpatient clinic of our medical center between July 20, 2015 and March 8, 2016. Patients with unilateral or bilateral lower-limb amputation and Syme amputation or higher who had been wearing prostheses for longer than 6 months were considered for the study. Among these patients, those who complained of low back pain that lasted for more than 3 months and agreed to participate in the study were selected prospectively. Patients who had spine surgery were also considered, and those who were able to walk with an activity level of K1 or higher were selected. The exclusion criteria were: inability to walk with an activity level of K0; inability to perform exercise due to cognitive impairment; hemiplegia and quadriplegia due to stroke or traumatic brain injury resulting in loss of the ability to walk or balance; upper limb amputation; and exercise treatment for low back pain at another hospital. The participants provided written informed consent and the protocol was approved by the Ethics Committee at Veterans Health Service Medical Center (IRB No. BOHUN 2015-05-007).

\section{Methods}

The goal of the exercise program was to strengthen the deep lumbar stabilizing muscles (transversus abdominis, lumbar multifidi, and internal obliques). The program was run twice a week for 8 weeks, with a total of 16 sessions. The exercise duration was 30 minutes including: 5 minutes of warming up, 20 minutes of the main exercise, 
and 5 minutes of cooling down. The exercise was performed under the supervision of a rehabilitation doctor and two physical therapists, in a group exercise format. Each warm-up and cooling down exercise was performed for 5 minutes within a range of motion without pain and included free gymnastics as well as static and dynamic stretching. The exercise program was developed by analyzing the characteristics of lower-limb amputees that differ from those of regular people, selecting exercises that could be performed by the amputees (Fig. 1). The program was based on the lumbar stabilization exercises used in the studies by Aluko et al. [10] and Moon et al. [4]. Among the participants included in this study, a model patient was selected to test the feasibility of the exercise. Twelve of the 14 exercises were separated into four sets of 3 exercises each and one set was performed in each session. The other 2 exercises, hollowing of the lower abdomen and lifting the trunk while prone, were performed at the beginning of each session. The first set of exercises was performed twice in the first week, and the second set was performed twice in the second week, and so on. After the 4th week, the exercises were repeated in the same order, resulting in a total of 16 sessions. During each exercise, the last movement was held for 10 seconds and this process was repeated five times [11]. Normal breathing was maintained during the exercise [12]. The therapist provided detailed verbal instructions for each routine beforehand, and the participants performed the exercises while watching the instructional video. All the subjects participated fully in the exercise program and none of them complained of aggravated low back pain or other discomfort.

\section{Evaluation methods}

A total of two evaluations were conducted; the first was carried out 1 week before the beginning of the program, and the second after completion of the 8-week program. To evaluate the severity of low back pain, the visual analog scale (VAS) scores were assessed. The Korean version of the Oswestry Disability Index (K-ODI) was used to evaluate the functional disability and quality of life [13]. The Thomas test was used to measure the iliopsoas muscle length in a physical examination [14]. When a patient pulled the back of one thigh towards their chest and lowered the other thigh passively, the angle between the thigh and the ground was measured. A trunk-raising test was used to measure abdominal muscle strength [6]. The trunk-raising test was graded according to the system,
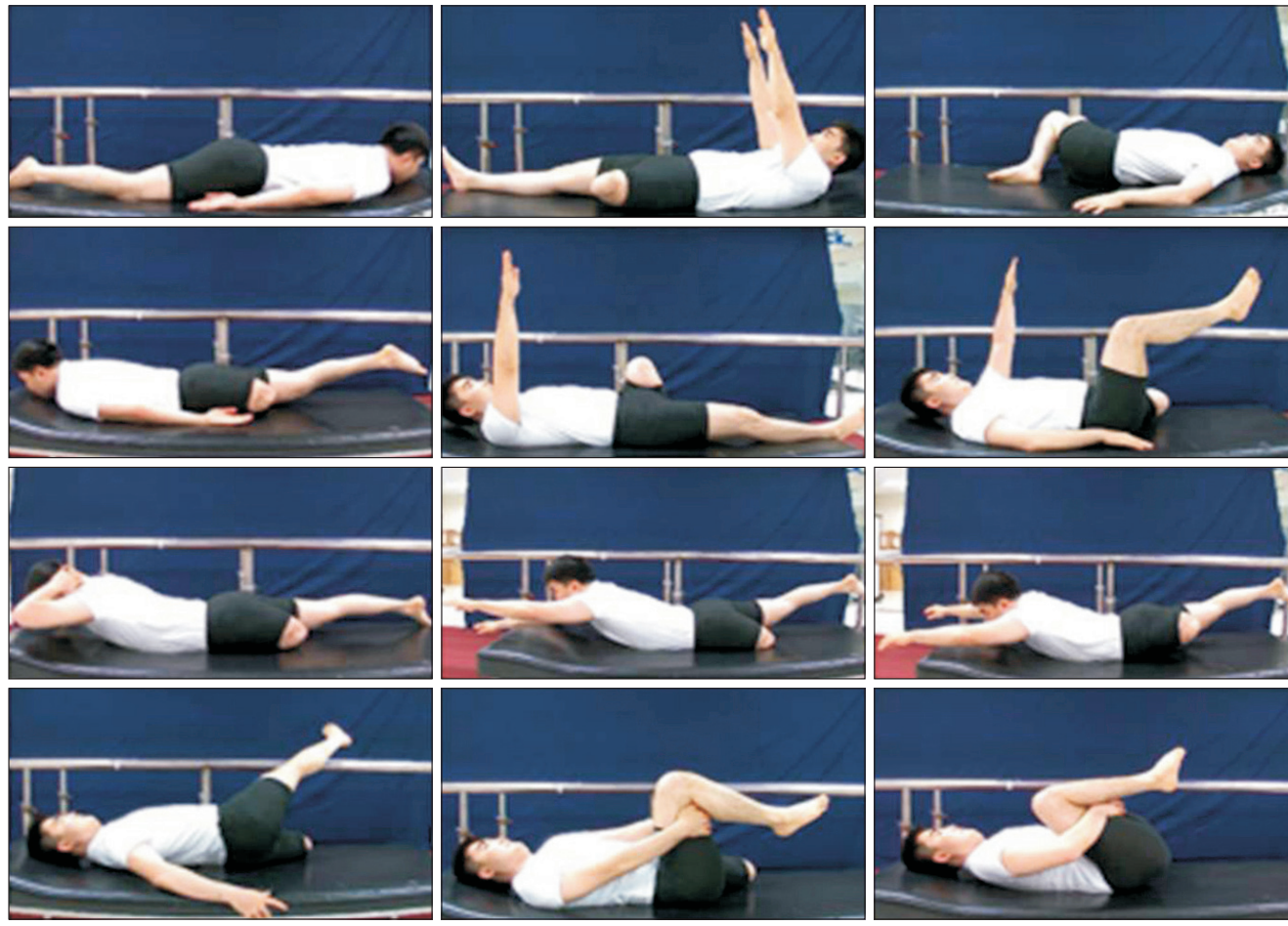

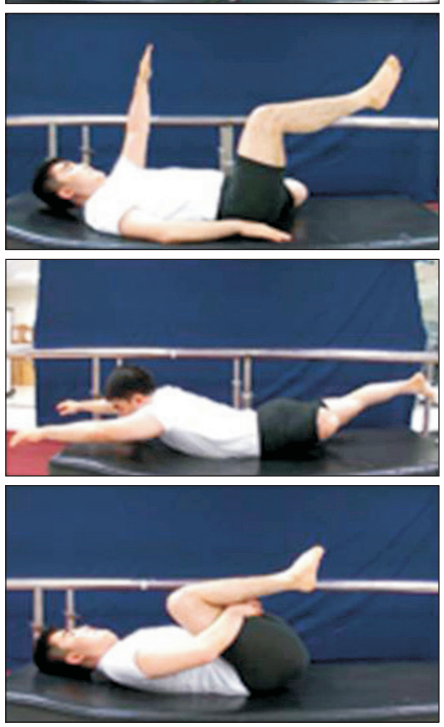

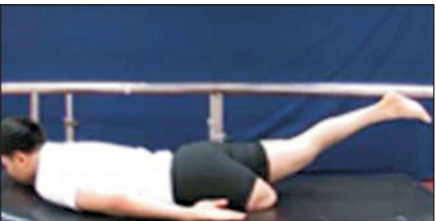
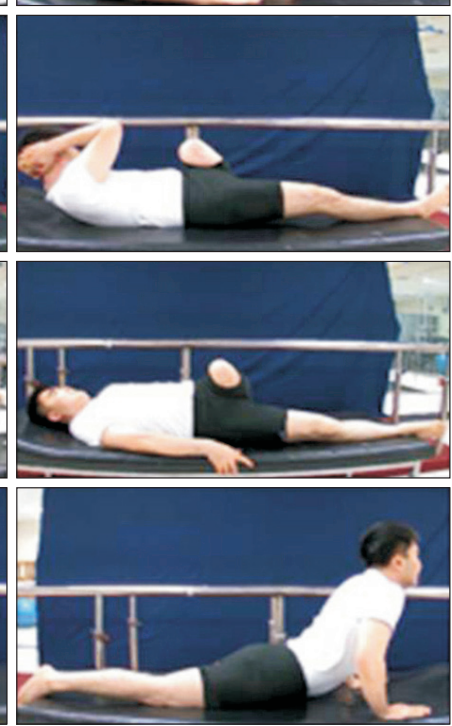

Fig. 1. Lumbar strengthening exercises. 
which states that the applied load varies according to the position of the arm when the examinee lifts the trunk while lying down. Back muscle strength was measured using the prone-lying trunk-raising test [6]. For stabilization, a strap was tied to the buttock and tibial region, and as needed, the examiner pressed on the patient's upperthigh region for extra stabilization. Scores ranged from 0 to 5 . All the examiners were instructed to successfully attempt a grade 3 test first, followed by other grades. Back extensor muscle endurance was evaluated using the Sorensen test [14]. Patients adopted a prone position, and the lower limbs were tied with a strap with the superior side of the iliac crest. First, stabilization was used while the examinees' arms rested on a chair in front of the bed. After starting the test, the examinees were instructed to lift their arms from the chair and lift their upper body into a horizontal position. The duration of stable position was recorded with a stop watch. Extra stabilization was achieved as the test proceeded while the examiner pressed on the patient's upper thigh. Physical examination of the affected and unaffected sides was carried out after removing the prosthesis. All the physical examinations were blindly conducted by two experienced rehabilitation doctors.

For objective evaluation of muscle strength, the Cybex (CSMi, Stoughton, MA, USA) examination equipment was used to measure the peak torque and total work at the angular velocities of $60^{\circ} / \mathrm{s}$ and $120^{\circ} / \mathrm{s}$ [15-18]. The examinees stood on the foothold and the region where the extension line of the iliac crest met the spine was identified as lumbar 4-5. Using this as a reference, the height of the foothold was adjusted so that the axis of rotation was positioned between lumbar 5 and sacral spine 1 . The waist was firmly stabilized with a pelvic girdle, and the height of the popliteal pad was adjusted. Both lower limbs were safely stabilized with femoral and tibial pads, and a sacral pad was moved from the front to the rear so that the axillary line passed through the center of the rotational axis. The scapular pad was positioned at the center of the scapula and connecting links at both ends of the chest pad were attached to the scapular pad to completely stabilize the upper body. The patients were instructed to hold the handle in front of the chest pad with both hands. Before the examination, preliminary tests were performed three times at each angular velocity so that the patients were familiar with the isokinetic strength test $[16,18]$.

\section{Statistical analysis}

To analyze the results, statistical analysis was conducted using SPSS version 18 (SPSS Inc., Chicago, IL, USA) for Windows and the Wilcoxon matched-pairs signed-rank test was performed to comparatively analyze the results before and after the exercise. The Mann-Whitney U-test was used to compare the results of clinical and isokinetic muscle strength tests after the exercise between the bilateral and the unilateral amputation groups based on the differences before and after exercise. Values were presented as mean \pm standard deviation, and $\mathrm{p}<0.05$ was considered statistically significant.

\section{RESULTS}

\section{General characteristics}

All 19 subjects who visited the rehabilitation outpatient clinic for chronic low back pain were enrolled prospectively. Mean age was $63.9 \pm 7.4$ years and the duration after amputation was $39.6 \pm 7.5$ years. Mean K-level was $2.6 \pm 0.6$ and the cause of amputation was trauma in all the patients. Amputation was performed on both sides for 3 patients, on the right side for 5 patients, and on the

Table 1. Subjects' baseline characteristics

\begin{tabular}{lc}
\hline \multicolumn{1}{c}{ Characteristic } & Value \\
\hline Age (yr) & $63.9 \pm 7.4$ \\
Duration after amputation (yr) & $39.6 \pm 7.5$ \\
\hline K-level & $2.6 \pm 0.6$ \\
\hline $\begin{array}{l}\text { Cause of amputation } \\
\quad \text { Trauma }\end{array}$ & $19(100)$ \\
\hline Side of amputation & \\
$\quad$ Right & $5(26.3)$ \\
$\quad$ Left & $11(57.9)$ \\
$\quad$ Both & $3(15.8)$ \\
\hline Level of amputation in unilateral lower & \\
limb amputees (n=16) & \\
$\quad$ Transfemoral & $5(31.3)$ \\
$\quad$ Knee disarticulation & $1(6.2)$ \\
\hline Transtibial & $9(56.3)$ \\
\hline Syme amputation & $1(6.2)$ \\
\hline
\end{tabular}

Values are presented as mean \pm standard deviation or number (\%). 
left side for 11 patients. The bilateral procedures included right and left transfemoral, right transfemoral and left transtibial, and long transfemoral amputations. Among the unilateral amputations, 5 were transfemoral, 1 was knee disarticulation, 9 were transtibial, and 1 was Syme amputation. The general characteristics of the subjects are summarized in Table 1.

\section{Comparison before and after the exercise}

VAS showed a statistically significant decrease after 8 weeks of exercise. The K-ODI showed a decrease after 8 weeks of exercise but the difference was not statistically significant ( $\mathrm{p}=0.343$ ). Iliopsoas muscle length showed no significant differences in both amputation and intact sites. Abdominal muscle strength and back extensor strength were significantly increased after the exercise $(\mathrm{p}<0.05)$. Back extensor endurance also showed an increase from $22.3 \pm 20.7$ seconds before the exercise to $46.8 \pm 35.1$ seconds after the exercise with a statistical significance $(\mathrm{p}<0.001)$ (Table 2).

The respective peak torque of the lumbar spine for the flexor and extensor muscles before the exercise was
146.4 $\pm 76.7 \mathrm{Nm}$ and $32.4 \pm 219.7 \mathrm{Nm}$ at $60^{\circ}$ of angular velocity, and $123.4 \pm 81.9 \mathrm{Nm}$ and $35.3 \pm 23.5 \mathrm{Nm}$ at $120^{\circ}$ of angular velocity (Table 3 ). After the program, the respective peak torques were $208.0 \pm 61.2 \mathrm{Nm}$ and $72.8 \pm 24.0$ $\mathrm{Nm}$ at $60^{\circ}$ of angular velocity, and $189.4 \pm 62.0 \mathrm{Nm}$ and $56.8 \pm 31.3 \mathrm{Nm}$ at $120^{\circ}$ of angular velocity, suggesting a statistically significant increase in peak torques of the flexor and extensor muscles at $60^{\circ}$ and $120^{\circ}$ of angular velocity. Total work at the lumbar spine for the flexor and extensor muscles at $60^{\circ}$ and $120^{\circ}$ of angular velocity also showed a statistically significant increase $(\mathrm{p}<0.05)$.

The mean value of the VAS, abdominal muscle strength, back extensor muscle strength, back extensor muscle endurance and isokinetic muscle strength test was improved in both bilateral and unilateral amputation groups. However, there were no significant differences before and after exercise between bilateral and unilateral amputation groups.

\section{DISCUSSION}

Chronic low back pain is experienced by more than

Table 2. Comparison of clinical parameters (pre- and post-exercise)

\begin{tabular}{lccc}
\hline & Pre & Post & p-value \\
\hline VAS & $4.6 \pm 2.2$ & $2.6 \pm 1.6$ & $0.001^{*}$ \\
\hline Oswestry questionnaire & $12.4 \pm 8.2$ & $11.4 \pm 8.2$ & 0.343 \\
\hline Iliopsoas muscle length & & & \\
Affected & $10.5 \pm 7.8$ & $13.4 \pm 11.8$ & 0.376 \\
\hline Unaffected & $10.5 \pm 7.4$ & $9.7 \pm 8.9$ & 0.909 \\
\hline Abdominal muscle strength & $4.4 \pm 0.7$ & $4.8 \pm 0.6$ & $0.007^{*}$ \\
Back extensor muscle strength & $2.6 \pm 0.6$ & $3.5 \pm 1.2$ & $0.007^{*}$ \\
Back extensor muscle endurance & $22.3 \pm 20.7$ & $46.8 \pm 35.1$ & $0.001^{*}$ \\
\hline
\end{tabular}

Values are presented as mean \pm standard deviation.

VAS, visual analogue scale.

${ }^{*} \mathrm{p}<0.05$, significant difference compared with pre-exercise.

Table 3. Changes in peak torque and total work of trunk flexors and extensors post-exercise

\begin{tabular}{|c|c|c|c|c|c|c|c|}
\hline & \multicolumn{2}{|c|}{ Pre } & \multicolumn{2}{|c|}{ Post } & \multicolumn{2}{|c|}{ p-value } \\
\hline & & Flexor & Extensor & Flexor & Extensor & Flexor & Extensor \\
\hline \multirow[t]{2}{*}{$60^{\circ} / \mathrm{s}$} & Peak torque $(\mathrm{Nm})$ & $146.4 \pm 76.7$ & $32.4 \pm 219.7$ & $208.0 \pm 61.2$ & $72.8 \pm 24.0$ & $0.002^{*}$ & $0.001^{*}$ \\
\hline & Total work (J) & $393.5 \pm 294.1$ & $104.7 \pm 103.0$ & $721.1 \pm 284.0$ & $297.4 \pm 141.7$ & $0.001^{*}$ & $0.001^{*}$ \\
\hline \multirow[t]{2}{*}{$120^{\circ} / \mathrm{s}$} & Peak torque (Nm) & $123.4 \pm 81.9$ & $35.3 \pm 23.5$ & $189.4 \pm 62.0$ & $56.8 \pm 31.3$ & $0.001^{*}$ & $0.005^{*}$ \\
\hline & Total work (J) & $643.1 \pm 868.4$ & $123.8 \pm 183.8$ & $1556.2 \pm 795.0$ & $346.7 \pm 333.3$ & $0.001^{*}$ & $0.002^{*}$ \\
\hline
\end{tabular}

Values are presented as mean \pm standard deviation.

${ }^{*} \mathrm{p}<0.05$, significant difference compared with pre-exercise. 
$50 \%$ of the general population [1]. Numerous studies have demonstrated the therapeutic effects of exercise on chronic low back pain [3-5]. Several ongoing studies are investigating the role of exercise in improving the stability of lumbar spine [11]. Park [19] reported that a 12-week core exercise program administered to 29 patients with chronic low back pain significantly improved the strength of lumbar extensor muscle and improved the stability of the lumbar spine.

Most of the existing studies related to pain in lowerlimb amputees have focused on phantom pain and residual limb pain. Treatment for chronic low back pain in lower-limb amputees involves mainly medications, surgery, and injection therapy. However, no studies analyzed the therapeutic effects of exercise in these patients.

In our study, an 8-week lumbar exercise program was provided to lower-limb amputees with chronic low back pain and the therapeutic effects were examined. The results showed a statistically significant decrease in chronic low back pain. Improvements in abdominal muscle strength, back extensor strength, and back extensor endurance were also observed. In addition, the isokinetic muscle strength test showed significant improvements in peak torque and total work at the lumbar spine flexion and extensor muscles after the program.

Our study was conducted to test the hypothesis that exercise improved pain and strengthened the abdominal and lumbar muscles in lower-limb amputees with chronic low back pain. The exercise program was designed by analyzing the patients' characteristics compared with controls and selecting the exercises that the amputees can perform. The program was based on lumbar stabilization exercises utilized in a study by Aluko et al. [10] and Moon et al. [4]. Abdominal hollowing refers to a curl-up exercise performed prior to abdominal muscle strengthening and is known to be effective for self-mobilizing the transversus abdominis and internal obliques [20]. However, because the necessary movements were not feasible by lower-limb amputees, lower abdominal hollowing, which leads to similar effects in a prone position and can be performed by lower-limb amputees, was performed during the warm-up exercise [10]. As constant repetition of the same movements may reduce the fun element, the 8-week program was designed to contain 4 sets of exercises, which were repeated four times. Nineteen participants performed all the exercises in the program. No pa- tients complained of acute aggravation of low back pain. Therefore, the lumbar strengthening exercise program used in our study was performed by all lower limb amputees without any apparent adverse effects.

After the 8-week exercise program, the VAS scores were significantly decreased in all patients followed by significant improvement in abdominal muscle strength, back extensor strength, and back extensor endurance. Back extensor strength is crucial for the correct posture of the lumbar spine and a slight lordosis of the back. In addition, previous studies showed that a decreased endurance of back extensor muscle is associated with low back pain [21-24]. The association of abdominal muscle strength with low back pain is still controversial. Friel et al. [6] conducted a comparative study examining the role of low back pain in physical impairment and functional deficits of 19 lower limb amputees. The results indicated that abdominal muscle strength was not significantly correlated with low back pain. However, abdominal muscle strength was improved by the exercise program in our study. Although the association remains controversial, the improvement of abdominal muscle strength is likely to reduce low back pain because weakness in the abdominal muscle triggers low back pain by inducing anterior pelvic tilt with lumbar hyperlordosis. We measured the length of the iliopsoas muscles bilaterally using the Thomas test. Research has shown that optimal extensibility of iliopsoas is needed to prevent low back pain [25]. Therefore, we investigated whether iliopsoas muscle length was improved after the exercise, but no statistically significant difference was found. These results are likely due to the low sensitivity and specificity of the Thomas test for the evaluation of iliopsoas muscle length [26].

Isokinetic muscle strength test was performed for objective evaluation of muscle strength and confirmed valid and reliable for the evaluation of muscle strength [18]. Hence, the test is commonly used as a highly reliable method to evaluate muscle strength and the peak torque of each joint during isokinetic exercise. At both $60^{\circ}$ and $120^{\circ}$ of angular velocity, the peak torque and total work at the flexion and extensor muscles significantly increased, which suggests improved flexion and extensor muscle strength based on the indices used for objective assessment. In general, trunk muscle extension requires stronger muscle strength than flexion, and the muscle strength ratio for extension and flexion is known to be 1.1:1 [18]. 
However, the decrease in muscle strength is reported to be larger in extension than in flexion for patients with low back pain $[27,28]$ resulting in a reverse phenomenon where the strength of flexion exceeded that of extension. Our study produced similar results.

K-ODI was used to evaluate the quality of life in this study. K-ODI is used to measure symptom improvement and aggravation in patients with low back pain via evaluation of motor functions. In the study of Friel et al. [6], the Oswestry scores were significantly higher in lowerlimb amputees with low back pain, who showed higher functional deficits. The Oswestry scores improved from 12.4 to 11.4 after exercise in this study without any statistical significance. These results are likely due to the fact that the Oswestry questionnaire was developed for the general population and cannot be fully applied to lowerlimb amputees. A tool for analyzing functional deficits in lower-limb amputees with low back pain needs to be developed in the future.

There were no significant differences in the values before and after exercise between the bilateral and unilateral amputation groups. These results are probably due to the relatively small sample size of the bilateral amputation group compared with that of the unilateral group (bilateral group $=3$, unilateral group $=16$ ). In this study, the exercise program was utilized regardless of transtibial or transfemoral amputation. However, a previous study by Devan et al. [29] showed that transfemoral amputation resulted in more frequent, intense, and bothersome back pain. Therefore, studies that differentiate between transtibial and transfemoral patients or bilateral and unilateral amputation patients are also needed to assess the effects of exercise accurately.

The limitations of this study are as follows. First, the sample size was small. Further studies are needed with larger sample sizes. Second, the cause of amputation was trauma in all the lower-limb amputees who participated in our study. The role of diabetic or vascular complications in lower-limb amputation has been increasing recently, and merits consideration in a future study. Third, although we provided an exercise video to guide the participants performing the exercise at home, no long-term follow-up was conducted.

In conclusion, following participation in our exercise program, lower-limb amputees with chronic low back pain showed a decrease in low back pain, an improve- ment in abdominal muscle strength, back extensor muscle strength, and endurance, and a significant increase in lumbar spine flexion and extension. We believe that our exercise program will help prevent secondary disability due to low back pain in lower-limb amputees, and restore their ability to return to society. It will also contribute to the expansion of treatment options for new amputees in the future.

\section{CONFLICT OF INTEREST}

No potential conflict of interest relevant to this article was reported.

\section{REFERENCES}

1. Rozenberg S. Chronic low back pain: definition and treatment. Rev Prat 2008;58:265-72.

2. Lawrence JP, Greene HS, Grauer JN. Back pain in athletes. J Am Acad Orthop Surg 2006;14:726-35.

3. Yi T, Lee JH, Lee YJ, Kim JS, Park JS, Kim DH, et al. Comparisons of spinal stabilization exercise and lumbar extensor strengthening exercise in chronic low back pain. J Korean Acad Rehabil Med 2008;32:570-5.

4. Moon HJ, Choi KH, Kim DH, Kim HJ, Cho YK, Lee KH, et al. Effect of lumbar stabilization and dynamic lumbar strengthening exercises in patients with chronic low back pain. Ann Rehabil Med 2013;37:110-7.

5. Kim DH, Yoon WY. The effect of core program exercise for lumbar extensor strength and pain of the patient with chronic low back pain. Proceedings of the 4th International Conference on Convergence Technology; 2014 Jul 2-5; Manila, Philippines.

6. Friel K, Domholdt E, Smith DG. Physical and functional measures related to low back pain in individuals with lower-limb amputation: an exploratory pilot study. J Rehabil Res Dev 2005;42:155-66.

7. Ehde DM, Smith DG, Czerniecki JM, Campbell KM, Malchow DM, Robinson LR. Back pain as a secondary disability in persons with lower limb amputations. Arch Phys Med Rehabil 2001;82:731-4.

8. Stam HJ, Dommisse AM, Bussmann HJ. Prevalence of low back pain after transfemoral amputation related to physical activity and other prosthesis-related parameters. Disabil Rehabil 2004;26:794-7.

9. Hendershot BD, Wolf EJ. Three-dimensional joint 
reaction forces and moments at the low back during over-ground walking in persons with unilateral lowerextremity amputation. Clin Biomech (Bristol, Avon) 2014;29:235-42.

10. Aluko A, DeSouza L, Peacock J. The effect of core stability exercises on variations in acceleration of trunk movement, pain, and disability during an episode of acute nonspecific low back pain: a pilot clinical trial. J Manipulative Physiol Ther 2013;36:497-504.

11. O'Sullivan PB, Phyty GD, Twomey LT, Allison GT. Evaluation of specific stabilizing exercise in the treatment of chronic low back pain with radiologic diagnosis of spondylolysis or spondylolisthesis. Spine (Phila Pa 1976) 1997;22:2959-67.

12. Akuthota V, Ferreiro A, Moore T, Fredericson M. Core stability exercise principles. Curr Sports Med Rep 2008;7:39-44.

13. Jeon CH, Kim DJ, Kim DJ, Lee HM, Park HJ. Crosscultural adaptation of the Korean version of the Oswestry Disability Index (ODI). J Korean Soc Spine Surg 2005;12:146-52.

14. Demoulin C, Vanderthommen M, Duysens C, Crielaard JM. Spinal muscle evaluation using the Sorensen test: a critical appraisal of the literature. Joint Bone Spine 2006;73:43-50.

15. Lee SH, Kim SJ. Isokinetic evaluation of the trunk flexors and extensors in chronic low back pain. J Korean Acad Rehabil Med 1994;18:248-55.

16. Suh DS, Kim MG, Kwon HK. Effect of isokinetic back training for patients with chronic low back pain. J Korean Acad Rehabil Med 1995;19:853-9.

17. Kim YC, Seo JH, Kim YH. Isokinetic measurement of trunk strength and analysis of related factors in healthy subjects. J Korean Acad Rehabil Med 1996;20: 929-38.

18. Shin JB, Kim SW, You S, Sohn HS, Cho YS. Concentric and eccentric isokinetic trunk muscle evaluation in chronic low back pain. J Korean Acad Rehabil Med 2001;25:1016-22.

19. Park SH. The effect of 12 weeks core exercise program on lumbar extension strength and stability of chronic low back pain patients. Korea J Sports Sci 2012;21: 1221-30.

20. Barnett F, Gilleard W. The use of lumbar spinal stabilization techniques during the performance of abdominal strengthening exercise variations. J Sports Med Phys Fitness 2005;45:38-43.

21. Biering-Sorensen F. Physical measurements as risk indicators for low-back trouble over a one-year period. Spine (Phila Pa 1976) 1984;9:106-19.

22. Chok B, Lee R, Latimer J, Tan SB. Endurance training of the trunk extensor muscles in people with subacute low back pain. Phys Ther 1999;79:1032-42.

23. Moffroid M, Reid S, Henry SM, Haugh LD, Ricamato A. Some endurance measures in persons with chronic low back pain. J Orthop Sports Phys Ther 1994;20:817.

24. Nourbakhsh MR, Arab AM. Relationship between mechanical factors and incidence of low back pain. J Orthop Sports Phys Ther 2002;32:447-60.

25. Kujala UM, Salminen JJ, Taimela S, Oksanen A, Jaakkola L. Subject characteristics and low back pain in young athletes and nonathletes. Med Sci Sports Exerc 1992;24:627-32.

26. Vigotsky AD, Lehman GJ, Beardsley C, Contreras B, Chung B, Feser EH. The modified Thomas test is not a valid measure of hip extension unless pelvic tilt is controlled. PeerJ 2016;4:e2325.

27. Mayer TG, Gatchel RJ, Kishino N, Keeley J, Mayer $\mathrm{H}$, Capra P, et al. A prospective short-term study of chronic low back pain patients utilizing novel objective functional measurement. Pain 1986;25:53-68.

28. Reid S, Hazard RG, Fenwick JW. Isokinetic trunkstrength deficits in people with and without low-back pain: a comparative study with consideration of effort. J Spinal Disord 1991;4:68-72.

29. Devan H, Tumilty S, Smith C. Physical activity and lower-back pain in persons with traumatic transfemoral amputation: a national cross-sectional survey. J Rehabil Res Dev 2012;49:1457-66. 